\title{
SARCOMA SINOVIAL CERVICAL: RELATO DE CASO
}

\author{
Müller J1; Branchi RN²
}

${ }^{1}$ Acadêmica de Medicina na Universidade de Caxias do Sul - UCS - Caxias do Sul (RS), Brasil. ${ }^{2}$ Médico Residente em Cirurgia Geral no Hospital Nossa Senhora da Conceição - Porto Alegre (RS), Brasil.

\section{Resumo}

INTRODUÇÃO: O Sarcoma Sinovial (SS) geralmente se apresenta com crescimento lento e surgimento em qualquer local da superfície corporal, sendo infrequente seu aparecimento na região cervical. Nesta topografia, pode cursar com dispneia, odinofagia e/ou disfagia, além de dor devido a compressão de estruturas nervosas pelo efeito de massa local. Deve-se fazer diagnóstico diferencial com patologias benignas (lipoma, tuberculose ganglionar), e tumores malignos (linfoma, carcinomas metastáticos, melanoma).

OBJETIVO: Relatar o caso de um paciente jovem diagnosticado com sarcoma sinovial cervical. A importância deste relato se encontra no fato de que o paciente apresentou uma lesão de rápida evolução e expansão, incomum para a patologia, em localização anatômica não usual, além de alertar para a importância de uma rápida suspeição clínica, já que o diagnóstico precoce é fator determinante para a morbiletalitade dessa doença.

DESCRIÇÃO DO CASO: D.S, sexo masculino, branco, 40 anos, natural de Caxias do Sul, sorologia positiva para Vírus da Imunodeficiência Humana (HIV) foi avaliado no Pronto Atendimento de um hospital na região da Serra Gaúcha, apresentando lesão expansiva em região cervical posterior à direita, com intensa dor local. A massa media aproximadamente $20 \mathrm{~cm}$ de diâmetro, apresentava bordos irregulares e odor fétido (Figura 1). O quadro teve início em Novembro de 2014 após aparecimento de uma lesão nodular que media aproximadamente $1 \mathrm{~cm}$ em região cervical posterior, associada com dor e 
com prurido local. Negava queixas respiratórias e dificuldade para deglutição. Apresentou perda ponderal de $12 \mathrm{~kg}$ em 4 meses. Realizou diversas consultas médicas, onde recebeu tratamento para tuberculose ganglionar, sem melhoras. A biópsia cutânea demonstrou inflamação crônica

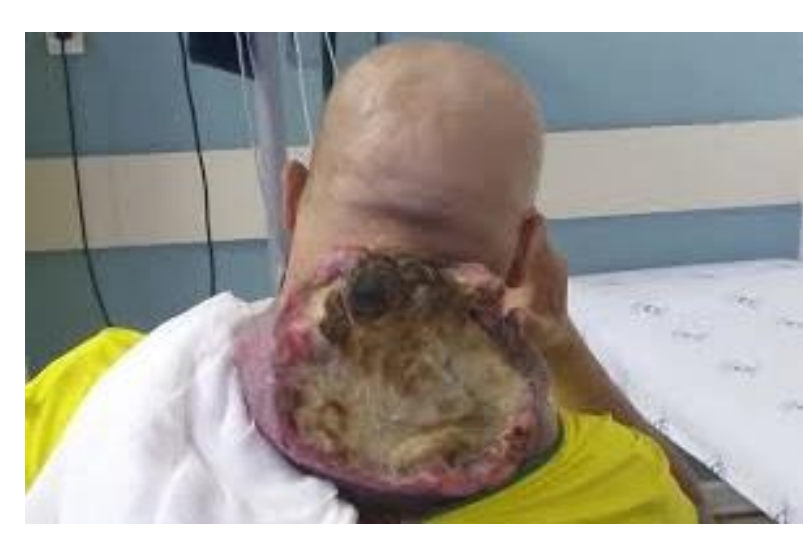

Figura 1: Sarcoma sinovial em região cervical posterior direita. com necrose de tipo caseosa, presença de células fusiformes e pesquisa para Bacilos Álcool-Ácido Resistentes (BAAR) e fungos negativas. A Ressonância Nuclear Magnética e a Tomografia Computadorizada com contraste sugeriram processo neoplásico, sem acometimento de estruturas vitais. $\mathrm{O}$ paciente foi encaminhado para serviço de oncologia cirúrgica especializado em cirurgia de cabeça e pescoço para seguimento do tratamento.

DISCUSSÃO: O SS deriva de uma semelhança histológica de células sinoviais, porém sua origem é desconhecida. Representa um dos tumores malignos de tecidos moles mais frequentes e difere tanto clinicamente como morfologicamente dos demais sarcomas, afetando principalmente homens na terceira década de vida. Os fatores de risco ainda são desconhecidos, impossibilitando estratégias de prevenção dessa patologia. Existem dois subtipos morfológicos: o monofásico e o bifásico. O primeiro, se apresenta apenas com um componente celular, com epitélio glandular ou fusiforme; enquanto que o segundo se apresenta com células de ambos os componentes. A maioria dos sarcomas sinoviais são caracterizados pela translocação cromossômica t $(\mathrm{X} ; 18)(\mathrm{p} 11 ; \mathrm{q} 11)$. A análise citogenética através do método FISH (Fluorescence in situ Hybridization) ou RT-PCR (Reverse Transcription Polymerase Chain Reaction), podem ser utilizados para detectar a translocação ou o produto da proteína do gene, auxiliando no diagnóstico de sarcoma sinovial. Exames de imagem como a Tomografia Computadorizada e a Ressonância Nuclear Magnética são necessárias para a avaliação da localização primária e da extensão da lesão seguida de biópsia. O tratamento consiste na ressecção cirúrgica da lesão com ou sem 
radioterapia adjuvante. $\mathrm{O}$ papel da quimioterapia ainda não está claro, mas pode ser empregada de forma adjuvante em casos selecionados.

Palavras Chave: Hipertensão Arterial Pulmonar; reação medicamentosa; carbamazepina. 


\section{Referências}

1. Fletcher C.D.M., Unni K.K., Mertens F. (Eds.): World Health Organization. Classificassion of Tumours. Pathology and Genetics of Tumours of Soft Tissue and Bone. IARC Press: Lyon 2002.

2. Tamborini E., Agus V., Mezzelani A., Riva C., Sozzi G., A zzarelli A., Pierotti MA., Pilotti S. Identification of a novel spliced variant of the SYT gene expressed in normal tissues ans in sinovial sarcoma. Br J Cancer. 2001;84(8):1087

3. Spurrell E.L, Fisher C., Thomas J.M, Judson I.R. Prognostic factors in advanced synovial sarcoma: an analysis of 104 patients treat at the Royal Marsden Hospital. Annals of Oncology 16: 437-444,2005 